\title{
(6) OPEN ACCESS \\ Patterns of bruising in preschool children with inherited bleeding disorders: a longitudinal study
}

\author{
Peter W Collins, ${ }^{1}$ Melinda Hamilton, ${ }^{2}$ Frank D Dunstan, ${ }^{3}$ Sabine Maguire, ${ }^{3}$ \\ Diane E Nuttall, ${ }^{3}$ Ri Liesner, ${ }^{4}$ Angela E Thomas, ${ }^{5}$ John Hanley ${ }_{1}^{6}$ Elizabeth Chalmers, ${ }^{7}$ \\ Victor Blanchette, ${ }^{8,9}$ Alison M Kemp ${ }^{3}$
}

'Department of Haematology, Institute of Infection and Immunity, School of Medicine Cardiff University, Cardiff, UK ${ }^{2}$ Department of Haematology, Ysbyty Gwynedd, Bangor, UK ${ }^{3}$ Institute of Primary Care and Public Health, School of Medicine Cardiff University, UK ${ }^{4}$ Department of Haematology, Great Ormond Street Hospital, London, UK

${ }^{5}$ Department of Haematology, Royal Hospital for Sick Children, Edinburgh, UK

${ }^{6}$ Department of Haematology,

Royal Victoria Infirmary,

Newcastle, UK

${ }^{7}$ Department of Haematology, Royal Hospital for Sick Children, Glasgow, UK

${ }^{8}$ Department of Paediatrics, University of Toronto, Toronto, Canada

'Division of Haematology/ Oncology, The Hospital for Sick Children, Toronto, Canada

\section{Correspondence to} Professor Peter W Collins, Department of Haematology, Institute of Infection and Immunity, School of Medicine Cardiff University, Haemophilia Centre, University Hospital of Wales, Heath Park, Cardiff CF14 4XN, UK;

collinspw@cardiff.ac.uk

Received 21 November 2015 Revised 6 June 2016

Accepted 7 June 2016

Published Online First

22 July 2016

\section{Linked}

- http://dx.doi.org/10.1136/ archdischild-2017-312847

\section{CrossMark}

To cite: Collins PW, Hamilton M, Dunstan FD, et al. Arch Dis Child 2017;102:1110-1117.

\section{ABSTRACT}

Objective The extent that inherited bleeding disorders affect; number, size and location of bruises in young children $<6$ years.

Design Prospective, longitudinal, observational study. Setting Community.

Patients 105 children with bleeding disorders, were compared with 328 without a bleeding disorder and classified by mobility: premobile (non-rolling/rolling over/ sitting), early mobile (crawling/cruising) and walking and by disease severity: severe bleeding disorder factor $\mathrm{V} \mid \mathrm{II} / \mathrm{IX/XI}<1 \mathrm{IU} / \mathrm{dL}$ or type 3 von Willebrand disease. Interventions Number, size and location of bruises recorded in each child weekly for up to 12 weeks.

Outcomes The interventions were compared between children with severe and mild/moderate bleeding disorders and those without bleeding disorders. Multiple collections for individual children were analysed by multilevel modelling.

Results Children with bleeding disorders had more and larger bruises, especially when premobile. Compared with premobile children without a bleeding disorder; the modelled ratio of means $(95 \% \mathrm{Cl})$ for number of bruises/ collection was 31.82 (8.39 to 65.42) for severe bleeding disorders and 5.15 (1.23 to 11.17$)$ for mild/moderate, and was 1.81 (1.13 to 2.23) for size of bruises. Children with bleeding disorders rarely had bruises on the ears, neck, cheeks, eyes or genitalia.

Conclusions Children with bleeding disorder have more and larger bruises at all developmental stages. The differences were greatest in premobile children. In this age group for children with unexplained bruising, it is essential that coagulation studies are done early to avoid the erroneous diagnosis of physical abuse when the child actually has a serious bleeding disorder, however a blood test compatible with a mild/moderate bleeding disorder cannot be assumed to be the cause of bruising.

\section{INTRODUCTION}

Bruising in children may result from normal activity, accidental trauma, physical abuse or haemostatic impairment. ${ }^{1-4}$ Studies have documented the number and pattern of bruises in physically abused and healthy children. ${ }^{5-7}$ The number of bruises that a child has increases with developmental stage $^{7-10}$ and certain sites are bruised more commonly in children who have been physically abused. ${ }^{9}$ There are few studies of the pattern of bruising in children with inherited bleeding disorders who are assumed to have more and larger bruises. Bruises $>1 \mathrm{~cm}$ contribute to higher paediatric bleeding scores in these children. ${ }^{11-13}$

\section{What is already known on this topic?}

- Bruising in children without an inherited bleeding disorder increases with mobility, but is very uncommon in premobile children in the absence of physical abuse.

- In children without an inherited bleeding disorder, bruises are rare on the ears, eyes, neck and genitalia at all mobility stages.

- There are no data available on the pattern of bruising to be expected in young children with an inherited bleeding disorder.

\section{What this study adds?}

- Children with severe inherited bleeding disorders have more, and larger, bruises than children without an inherited bleeding disorder, especially when premobile.

- The location of bruises on children with an inherited bleeding disorder differs from those without an inherited bleeding disorder.

- At all mobility stages, for children with or without an inherited bleeding disorder, bruises were rare on the ears, neck, cheeks, eyes or genitalia.

Young children are the most vulnerable for both undiagnosed bleeding disorders and physical abuse. Diagnosis is based on an assessment of bruises in the context of the proposed history and laboratory investigations (http://www.rcpch.ac.uk/news/rcpchlaunches-2nd-edition-child-protection-companion). The interpretation of laboratory haemostatic tests may be difficult. ${ }^{1-4}{ }^{14}$ If a mild laboratory abnormality is assumed to be the cause of bruising then abuse may go unrecognised but, if a bleeding disorder is missed, a family may be inappropriately accused of abuse. Interpretation of clinical findings may differ between paediatricians and haematologists ${ }^{15}$ and both conditions may coexist. ${ }^{16}$ This study aims to characterise bruising in children with bleeding disorders at different developmental stages, in comparison to children without bleeding disorders. ${ }^{7}$ The data set generated will help paediatricians and haematologists to assess bruising in young children and give an indication of the pattern of bruising to be expected from daily activities of children with a bleeding disorder. 


\section{METHODS}

This prospective, longitudinal study recruited children age $<6$ years from six haemophilia centres. Children without bleeding disorders were from well-baby clinics, hospital outpatient clinics, and mother and baby groups in South Wales and have been described previously. ${ }^{7}$ Bleeding disorders were recorded as haemophilia, factor XI deficiency, von Willebrand disease (VWD) or platelet disorders; other bleeding disorders were not recruited. Severe bleeding disorders were defined as factor VIII/ IX/XI $<1$ IU/dL or type 3 VWD. Mild/moderate bleeding disorders were defined as factor VIII/IX/XI $\geq 1 \mathrm{IU} / \mathrm{dL}$, type 1 and type 2 VWD. Children with mild and moderate bleeding disorder were not analysed separately due to an insufficient number of subjects. Children were subdivided according to prophylactic replacement therapy use.

Parents gave written consent and were trained to record bruise number, location and size on a body map. Developmental stages were defined as premobile (non-rolling, rolling over and sitting), early mobile (crawling or cruising) and walking. Size was the maximum dimension measured with a tape measure. These data 'collections' were recorded once weekly for up to 12 weeks. A child could contribute up to 12 weekly collections at each developmental stage, subsequent collections were excluded. In a validation exercise, 40 data collections from 40 non-bleeding disorder children were performed independently by both a carer and researcher and compared.

Bruises were recorded in 38 locations. These were grouped into 18 locations, combining locations on both sides of the body where laterality was considered unimportant or where bruises were rare. The 'facial-T' was defined as forehead, nose, lips or chin. ${ }^{17}$ The 'head' was the area within the hairline. 'Front trunk' included chest and abdomen. 'Rear trunk' included the back above buttocks. Bruises from immunisations or venepuncture were excluded. Total bruise size was the sum of the maximum diameters of all bruises in a collection.

\section{Statistical analysis}

Data were summarised using mean and SD or count and proportions and compared between children with and without bleeding disorders. Longitudinal analysis was performed on the number and size of bruises using multilevel modelling, with collections nested within children, to allow comparisons between groups of children with different numbers of collections; nonbleeding disorder children were the reference group.

For bruise number, a model with a Poisson distribution and $\log$ link function was used. Comparisons were expressed as ratio of means. For bruises $>1 \mathrm{~cm}$ a logistic model was employed, leading to an OR for a bruise $>1 \mathrm{~cm}$. For bruise size a lognormal distribution was used, and a $\gamma$ distribution for total bruise size, with a better fit arising from adding one to total size; distributions were chosen following explorations of the distributions of the data. From the multilevel modelling, estimates were derived of the percentage of variation in bruise counts across collections due to differences between children, as opposed to variation in the counts longitudinally within children.

The analysis of bruise size was based only on collections in which all sizes were recorded, in case there was a tendency to record sizes in certain locations, or of certain sizes, preferentially over others. Analysis was performed using Stata V.13.

\section{RESULTS}

The study enrolled 105 children with bleeding disorders, mean age (range) $2.6(0.1-5.8)$ years and 328 children without a bleeding disorder mean age (range) 1.6 (0-5.8) years. ${ }^{7}$ There were 58 children with severe and 47 with mild/ moderate bleeding disorders. The mild/moderate group had a median (IQR) (range) factor level of 23 (11-30) (3-35 IU/dL). Two patients with platelet function disorders are reported individually. Thus $103 \mathrm{BD}$ children are included in the main analysis (table 1).

\section{Validation}

The 40 data collections in the validation cohort had a mean (SD) 2.35 (2.2) bruises/child, range 0-7. There was complete agreement between carers and researcher regarding bruise number and location, the mean difference between the size measurement was $<1 \mathrm{~mm}$.

\section{Number of bruises}

There were 5613 bruises recorded from 1146 collections in 103 children with bleeding disorders, and 3523 bruises from 2570 collections in 328 children without a bleeding disorder.

\section{Premobile children}

Premobile children with mild/moderate bleeding disorders had the same proportion of collections with at least one bruise as those without bleeding disorders (7\%). However, children with severe bleeding disorders had at least one bruise in $52 \%$ of collections.

Premobile children with bleeding disorders had a higher mean number of bruises/collection than those without a

Table 1 Characteristics of children with and without inherited bleeding disorders

\begin{tabular}{|c|c|c|c|c|}
\hline & $\begin{array}{l}\text { Non-bleeding } \\
\text { disorder }\end{array}$ & \multicolumn{2}{|c|}{$\begin{array}{l}\text { Severe bleeding } \\
\text { disorder }\end{array}$} & $\begin{array}{l}\text { Mild/ } \\
\text { moderate } \\
\text { bleeding } \\
\text { disorder }\end{array}$ \\
\hline Subjects & 328 & \multicolumn{2}{|l|}{57} & 46 \\
\hline $\begin{array}{l}\text { Age at enrolment } \\
\text { in years } \\
\text { Mean (SD) }\end{array}$ & $1.58(1.45)$ & \multicolumn{2}{|l|}{$2.66(1.66)$} & 2.43 (1.78) \\
\hline Gender (M/F) & $\begin{array}{l}145(46 \%) / 168 \\
(54 \%)\end{array}$ & \multicolumn{2}{|c|}{$56(98 \%) / 1(2 \%)$} & $\begin{array}{l}31(69 \%) / 14 \\
(31 \%)\end{array}$ \\
\hline Missing data & 15 & \multicolumn{2}{|l|}{0} & 1 \\
\hline Diagnosis & & $\begin{array}{l}\text { No } \\
\text { prophylaxis }\end{array}$ & Prophylaxis & \\
\hline Haemophilia* & & $27(47 \%)$ & $24(42 \%)$ & $23(50 \%)$ \\
\hline VWD & NA & $6(11 \%)$ & $0(0 \%)$ & $23(50 \%)$ \\
\hline Collectionst & & $\begin{array}{l}\text { No } \\
\text { prophylaxis }\end{array}$ & Prophylaxis & \\
\hline Pre mobile & 1010 (39\%) & $64(18 \%)$ & $0(0 \%)$ & 59 (11\%) \\
\hline Early mobile & $478(19 \%)$ & $64(18 \%)$ & $12(5 \%)$ & $70(13 \%)$ \\
\hline Walking & $1082(42 \%)$ & $229(64 \%)$ & $255(95 \%)$ & $393(75 \%)$ \\
\hline Total & 2570 & 357 & 267 & 522 \\
\hline \multicolumn{5}{|c|}{$\begin{array}{l}\text { The children with a bleeding disorder (BD) had mean (range) } 11 \text { (1-36) collections/ } \\
\text { child. At the first collection for the bleeding disorder group, } 15 \text { children were } \\
\text { premobile, } 10 \text { early mobile and } 78 \text { walking. At first collection for the non-bleeding } \\
\text { disorder group } 133 \text { children were premobile, } 43 \text { early mobile and } 152 \text { walking. } \\
\text { *The haemophilia group included } 61 \text { with haemophilia A, } 10 \text { with haemophilia B, } 3 \\
\text { with factor XI deficiency. All children with factor XI deficiency were in the non-severe } \\
\text { group. } \\
\text { tSome subjects contributed collections in more than one developmental stage; of the } \\
431 \text { children (excluding the } 2 \text { with platelet disorders) } 356 \text { remained in a single } \\
\text { developmental stage, } 65 \text { crossed two and } 10 \text { crossed three stages. Some children } \\
\text { moved from on demand to prophylaxis. The two patients with platelet function } \\
\text { disorders have not been included. } \\
\text { NA, not applicable; VWD, von Willebrand disease. }\end{array}$} \\
\hline
\end{tabular}


bleeding disorder. Compared with the non-bleeding disorder group the modelled ratio of means $(95 \% \mathrm{CI})$ for number of bruises/collection for severe bleeding disorders was 31.82 (8.39 to 65.42 ) and 5.15 (1.23 to 11.17) for the mild/moderate group (table 2).

\section{Early mobile children}

In early mobile children with a severe bleeding disorder, $98 \%$ of collections had at least one bruise. Children with both severe and mild/moderate bleeding disorders had more bruises/collection than children without a bleeding disorder, but the difference was less marked than among premobile children (table 2).

\section{Walking children}

Among walking children, the number of bruises/collection, and the percentage of collections with at least one bruise, were similar for the mild/moderate and severe bleeding disorder groups but more than for children without a bleeding disorder. The differences were less marked than in premobile and early mobile children (table 2).

\section{Interpatient and intrapatient variations}

Among premobile children without a bleeding disorder, the percentage of variation due to random variation over time, as opposed to differences between children, was 64\%; for children with a bleeding disorder of any severity, this was lower at $1 \%$. For early mobile children the corresponding values were $42 \%$ and $4 \%$, while for walking children they were $25 \%$ and $16 \%$. Thus, the amount of variation due to random variation over time declined among non-bleeding disorder children as developmental stages increased, in direct contrast to those with a bleeding disorder.
Haemophilia and VWD and effect of prophylaxis

The number of bruises/collection was similar when comparing VWD with haemophilia, or between those receiving, or not receiving, prophylaxis (table 2).

\section{Size of bruises}

Children with severe bleeding disorders had larger bruises than non-bleeding disorder children at all developmental stages. The modelled means (95\% CI) for size of bruises for severe premobile bleeding disorders was 1.81 (1.22 to 2.23) (table 3).

\section{Bruises larger than $1 \mathrm{~cm}$}

Across all developmental stages children with bleeding disorders had more bruises of $>1 \mathrm{~cm}$ than non-bleeding disorder children. Premobile children without a bleeding disorder had at least one bruise of $>1 \mathrm{~cm}$ in $1.0 \%$ of collections, compared with $3.4 \%$ of mild/moderate and $24.6 \%$ of severe bleeding disorders. There were no collections with at least five bruises of $>1 \mathrm{~cm}$ in any premobile group. Premobile children with severe bleeding disorders had more bruises/collection of $>1 \mathrm{~cm}$ than children without a bleeding disorder (modelled OR 112.6, 95\% CI 11.99 to 378.3 ). Early mobile children with a severe bleeding disorder had at least five bruises of $>1 \mathrm{~cm}$ in $22 \%$ of collections (table 3 ). Total bruise size per collection at each mobility stage is shown in table 3.

\section{Location of bruises}

Premobile children

Bruises on the cheeks, ears, neck, buttocks, eyes and genitalia were absent or extremely rare ( $<0.5 \%$ of collections) in children with bleeding disorders, regardless of severity, and absent in children without a bleeding disorder (table 4 and figures 1-3).

Table 2 Number of bruises in children with and without inherited bleeding disorders

\begin{tabular}{|c|c|c|c|}
\hline & $\begin{array}{l}\text { Number of bruises per collection } \\
\text { Mean (SD) }\end{array}$ & $\begin{array}{l}\text { Number and percentage of } \\
\text { collections with at least one bruise }\end{array}$ & $\begin{array}{l}\text { Modelled ratio of mean } \\
\text { number of bruises }(95 \% \mathrm{Cl})\end{array}$ \\
\hline \multicolumn{4}{|l|}{ Premobile } \\
\hline Non-BD & $0.09(0.35)$ & $68 / 1010(7 \%)$ & 1 \\
\hline Mild/moderate BD & $0.19(0.80)$ & $4 / 59(7 \%)$ & $5.15(1.23 \text { to } 11.17)^{*}$ \\
\hline Severe BD & $1.06(1.48)$ & $33 / 64$ (52\%) & $31.82(8.39 \text { to } 65.42)^{*}$ \\
\hline \multicolumn{4}{|l|}{ Early mobile } \\
\hline Non-BD & $0.80(1.19)$ & $218 / 478(46 \%)$ & 1 \\
\hline Mild/moderate BD & $2.53(4.78)$ & $39 / 70(56 \%)$ & $2.96(1.41 \text { to } 4.42)^{*}$ \\
\hline Severe BD off prophylaxis & $7.81(7.30)$ & $63 / 64(98 \%)$ & $8.28(3.34 \text { to } 13.53)^{*}$ \\
\hline \multicolumn{4}{|l|}{ Walking } \\
\hline Non-BD & $2.82(2.77)$ & $852 / 1082(79 \%)$ & 1 \\
\hline \multicolumn{4}{|l|}{ Mild/moderate BD } \\
\hline All patients & $5.28(5.22)$ & $332 / 393(84 \%)$ & $1.66(1.20 \text { to } 1.98)^{*}$ \\
\hline Haemophilia & $4.11(3.30)$ & $174 / 205(85 \%)$ & NA \\
\hline VWD & $6.57(6.48)$ & $158 / 188(84 \%)$ & NA \\
\hline \multicolumn{4}{|l|}{ Severe BD off prophylaxis } \\
\hline All patients & $5.62(5.83)$ & $208 / 229(91 \%)$ & $2.13(1.53 \text { to } 2.55)^{*}$ \\
\hline Haemophilia & $4.57(4.14)$ & $164 / 184(89 \%)$ & NA \\
\hline VWD & $9.91(9.03)$ & $44 / 45(98 \%)$ & NA \\
\hline \multicolumn{4}{|l|}{ Severe BD on prophylaxis } \\
\hline All patients & $5.57(4.50)$ & $232 / 255(91 \%)$ & $1.80(1.2 \text { to } 2.15)^{*}$ \\
\hline Haemophilia & $5.69(4.54)$ & $223 / 246(91 \%)$ & NA \\
\hline VWD & $2.22(0.67)$ & 9/9 (100\%) & NA \\
\hline
\end{tabular}

NA is not analysed due to insufficient numbers of collections.

*Indicates a statistically significant difference from children without a bleeding disorder. There were insufficient subjects to investigate VWD separately in the premobile and early mobile groups. Prophylaxis is predominantly used for mobile children with severe bleeding disorders and so can only be reported in the walking group.

$\mathrm{BD}$, bleeding disorder; VWD, von Willebrand disease. 


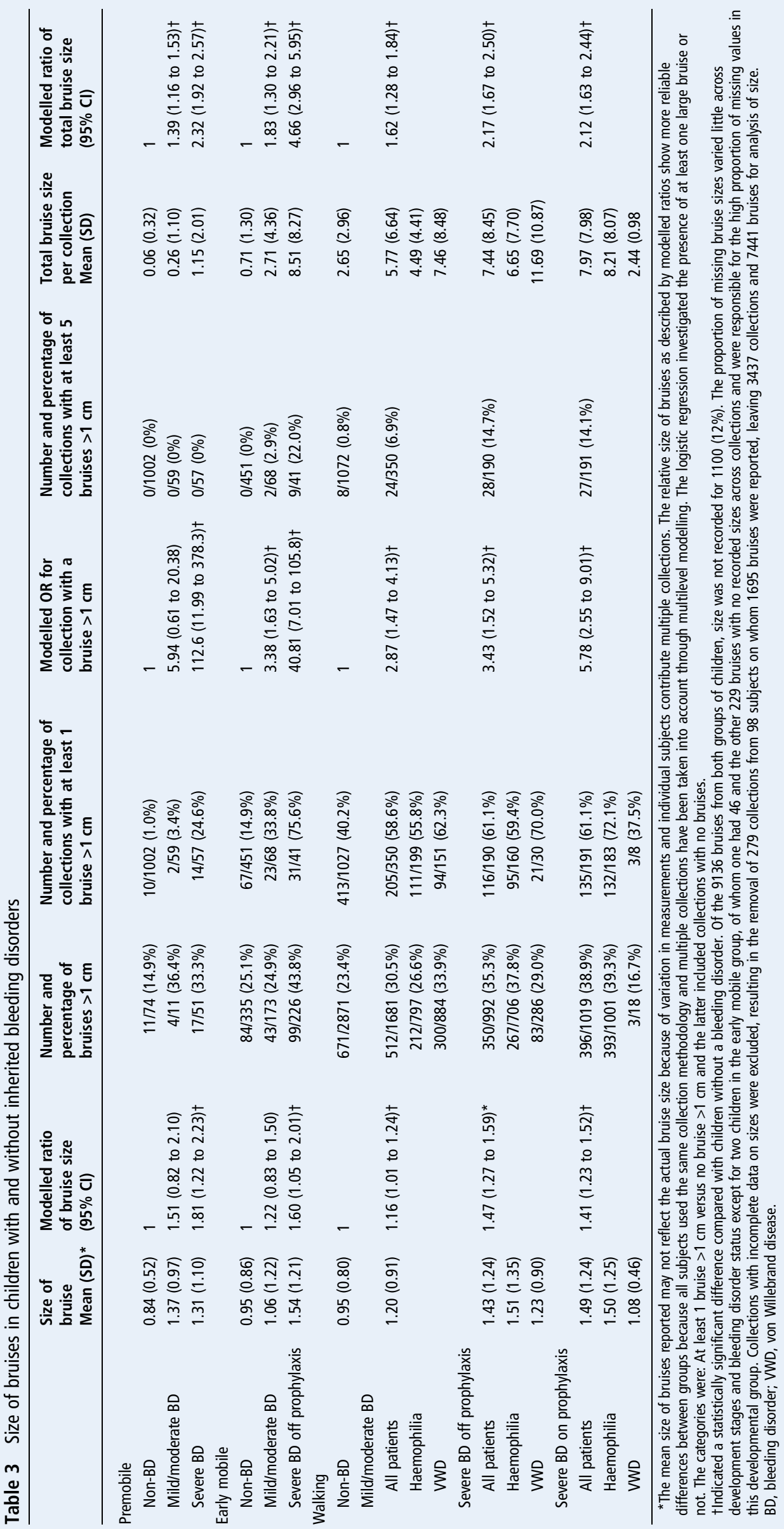


Table 4 Percentage of collections with at least one bruise at the location indicated

\begin{tabular}{|c|c|c|c|c|c|c|c|c|c|c|}
\hline \multirow[b]{2}{*}{ Location } & \multicolumn{3}{|c|}{ Premobile (number of collections) } & \multicolumn{3}{|c|}{$\begin{array}{l}\text { Early mobile } \\
\text { (number of collections) }\end{array}$} & \multicolumn{4}{|c|}{ Walking (number of collections) } \\
\hline & $\begin{array}{l}\text { Non-BD } \\
(1010)\end{array}$ & $\begin{array}{l}\text { Mild/ } \\
\text { moderate } \\
\text { BD (59) }\end{array}$ & $\begin{array}{l}\text { Severe } \\
\text { BD (64) }\end{array}$ & $\begin{array}{l}\text { Non-BD } \\
(479)\end{array}$ & $\begin{array}{l}\text { Mild/ } \\
\text { moderate } \\
\text { BD (70) }\end{array}$ & $\begin{array}{l}\text { Severe } \\
\text { BD (64) }\end{array}$ & $\begin{array}{l}\text { Non-BD } \\
(1082)\end{array}$ & $\begin{array}{l}\text { Mild/ } \\
\text { moderate } \\
\text { BD (393) }\end{array}$ & $\begin{array}{l}\text { Severe BD off } \\
\text { prophylaxis } \\
(229)\end{array}$ & $\begin{array}{l}\text { Severe BD on } \\
\text { prophylaxis } \\
(255)\end{array}$ \\
\hline Below knees & 1 & 2 & 10 & 21 & 27 & 78 & 64 & 72 & 76 & 80 \\
\hline Left cheek & 0 & 0 & 0 & 2 & 1 & 2 & 1 & 2 & 1 & 8 \\
\hline Right cheek & 0 & 0 & 0 & 3 & 6 & 2 & 2 & 3 & 3 & 2 \\
\hline Left ear & 0 & 0 & 0 & 0 & 0 & 3 & 0 & 1 & 0 & 0 \\
\hline Right ear & 0 & 0 & 0 & 0 & 1 & 0 & 0 & 0 & 1 & 0 \\
\hline Head & 1 & 3 & 2 & 7 & 11 & 6 & 3 & 8 & 6 & 11 \\
\hline Facial-T & 1 & 0 & 3 & 14 & 20 & 16 & 11 & 18 & 16 & 19 \\
\hline Eyes & 0 & 0 & 2 & 2 & 1 & 0 & 1 & 2 & 2 & 2 \\
\hline Front trunk & 0 & 3 & 8 & 0 & 3 & 23 & 4 & 16 & 25 & 21 \\
\hline Rear trunk & 1 & 0 & 11 & 2 & 3 & 16 & 10 & 21 & 17 & 17 \\
\hline Neck & 0 & 0 & 0 & 0 & 1 & 0 & 0 & 1 & 0 & 0 \\
\hline Buttocks & 0 & 0 & 0 & 0 & 9 & 4 & 5 & 10 & 6 & 8 \\
\hline Genitalia & 0 & 0 & 0 & 0 & 0 & 3 & 0 & 0 & 2 & 0 \\
\hline Upper arms & 0 & 2 & 19 & 1 & 11 & 34 & 9 & 27 & 30 & 33 \\
\hline Lower arms & 0 & 0 & 5 & 1 & 16 & 39 & 12 & 21 & 28 & 30 \\
\hline Hands & 0 & 0 & 2 & 1 & 0 & 13 & 1 & 3 & 3 & 8 \\
\hline Front thighs & 1 & 2 & 10 & 4 & 23 & 23 & 17 & 27 & 21 & 30 \\
\hline Back thighs & 0 & 0 & 6 & 1 & 4 & 11 & 7 & 17 & 16 & 19 \\
\hline Feet & 0 & 2 & 14 & 1 & 3 & 9 & 4 & 6 & 13 & 9 \\
\hline Total & 7 & 7 & 52 & 46 & 56 & 98 & 79 & 85 & 91 & 91 \\
\hline
\end{tabular}

Pre-mobile group
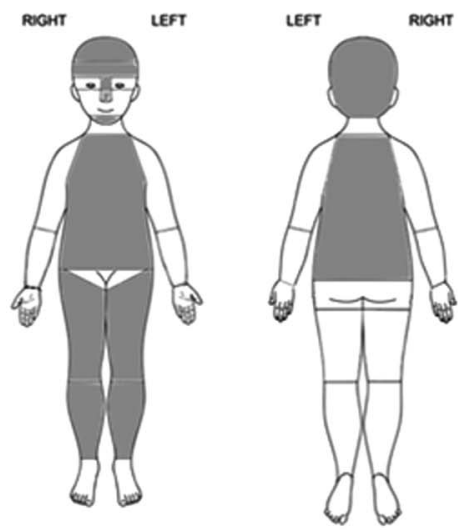

Control - non Bleeding Disorder

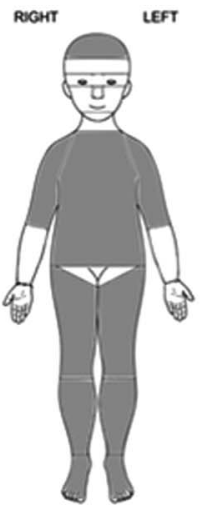

Mild/moderateBleeding Disorde
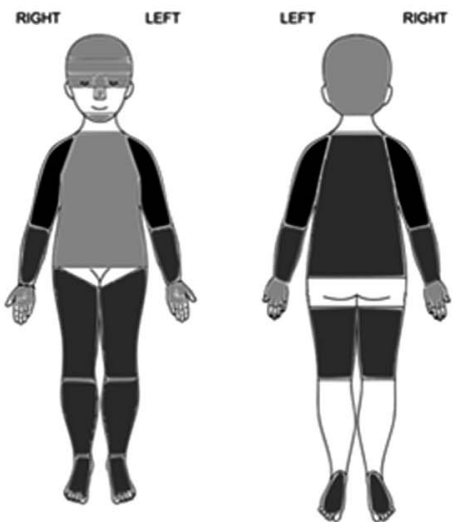

Severe Bleeding Disorder

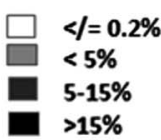

Figure 1 Location of bruises in premobile children. The figure shows the proportion of collections in which there was at least one bruise at the location indicated.

Among children without a bleeding disorder and those with $\mathrm{mild} /$ moderate bleeding disorders, no more than $1 \%$ and $3 \%$ of collections, respectively, had a bruise in any other location. Children with severe bleeding disorders had substantially more collections with bruises ( $>10 \%$ of collections) predominantly on upper arms, feet, rear trunk, front of thighs and below knee.
Early mobile children

Bruising was uncommon ( $\leq 3 \%$ of collections) across all groups on the ears, neck, eyes, front trunk, left cheek and genitalia. Bruising to the buttocks was recorded in bleeding disorders. Predominant sites of bruising in children without a bleeding disorder were below the knee and facial-T. The 


\section{Early Mobile}

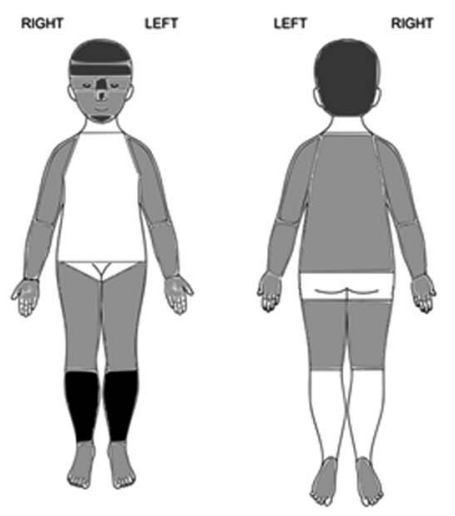

Non Bleeding Disorder

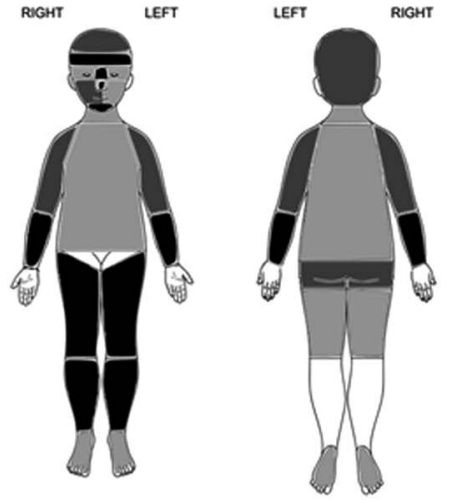

Mild/moderateBleeding Disorder
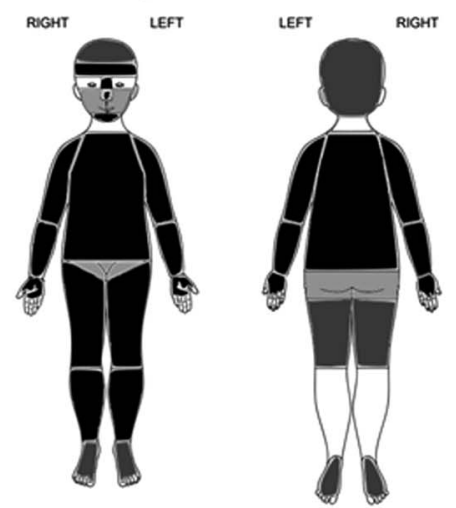

Severe Bleeding Disorder

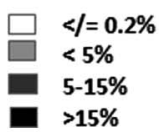

Figure 2 Location of bruises in early mobile children. The figure shows the proportion of collections in which there was at least one bruise at the location indicated.

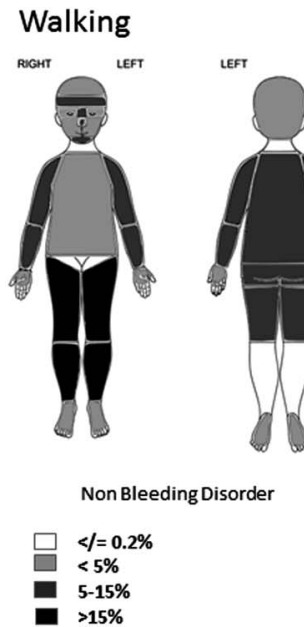

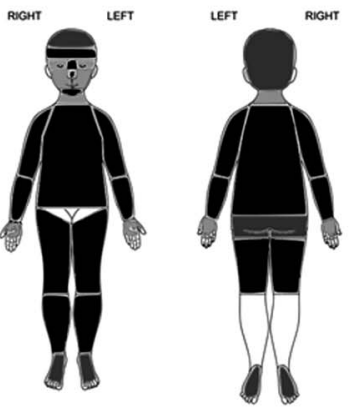

Mild/moderateBleeding Disorder
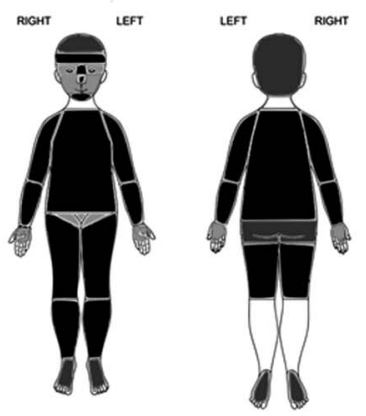

Severe Bleeding Disorder off Prophylaxis
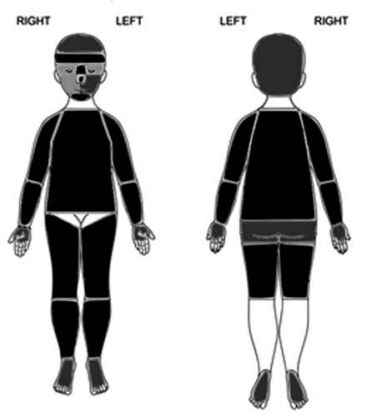

Severe Bleeding Disorder on Prophylaxis

Figure 3 Location of bruises in walking children. The figure shows the proportion of collections in which there was at least one bruise at the location indicated.

proportion of collections with bruising to the facial-T and head was similar across the three groups. In children with severe bleeding disorders, bruises were more frequent on the limbs, trunk, feet and hands than in the other two groups (with the exception of front of thighs in mild/moderate bleeding disorders).

\section{Walking children}

Bruises below the knee predominated, but were absent or reported in $\leq 3 \%$ of collections across all groups on the ears, right cheek, eyes, neck and genitalia; however bruises on the buttocks were recorded. Children with bleeding disorders had more bruises than those without bleeding disorders on the head, cheeks, front and rear trunk, upper and lower arms, facial-T, front and back of thighs, hands and feet. The proportion of collections with at least one bruise was similar for children with mild/moderate and severe bleeding disorders at most locations.

\section{Platelet disorders}

One early mobile child with Glanzmann's thrombasthenia had 526 bruises in 12 collections: mean (range) 43.8 (29-72) bruises/collection. Mean size was $1.3 \mathrm{~cm}$ and the largest mean size was on the front and rear trunk. Bruises were very rare on the cheeks, hands, eyes, ears and genitalia although they were observed on the neck.

One child with hereditary macrothrombocytopenia contributed 3 premobile and 12 walking collections. No bruises were recorded when premobile. When walking there was a mean (range) 8.8 (1-16) bruises/collection. Bruises were not reported on the ears, cheeks, eyes neck, buttocks or genitalia. Most bruises 
were below the knee $(75.5 \%)$ and facial-T (9.4\%). Mean size was $0.94 \mathrm{~cm}$ and $67 \%$ of collections had at least one bruise $>1 \mathrm{~cm}$.

\section{DISCUSSION}

This study shows that children with bleeding disorders have more bruises than children without bleeding disorders and the difference is most marked at the premobile developmental stage. Children with severe bleeding disorders have significantly larger bruises compared with non-bleeding disorders at all mobility stages. The location of bruises differs between those with or without a bleeding disorder, but in all groups bruising on the ears, neck, cheeks, eyes or genitalia was rare. This is significant because bruising in these sites is indicative of physical abuse which should be investigated even in children with severe bleeding disorders. ${ }^{918-20}$

Bruising in premobile children is uncommon and warrants investigations for potential physical abuse. ${ }^{6}$ The fact that premobile children with a severe bleeding disorder had bruising in $>50 \%$ of collections highlights the need for laboratory investigations for severe bleeding disorders in combination with child protection assessment. These findings may also explain why premobile children with undiagnosed severe bleeding disorders are commonly investigated for physical abuse. ${ }^{1-4}$ Our results suggest that a blood test compatible with a mild/moderate bleeding disorder cannot be assumed to be the cause of bruising in premobile children, because the proportion of collections with at least one bruise was the same as non-bleeding disorder children, and a rigorous assessment for possible abuse is required.

A key question addressed in this study is whether bruise location in children with bleeding disorders differs from those without a bleeding disorder. The small number of bruises in collections from premobile children without bleeding disorders or with mild/moderate bleeding disorders meant that no particular locations predominated in these groups. There were sites that were rarely bruised regardless of severity of bleeding disorder or mobility stage which include ears, neck, cheeks, eyes or genitalia.

Once children started to achieve independent mobility there were sites that were affected in all groups (below the knees, facial-T, head). These sites were predominantly on the front of the body and over bony prominences. The trunk, buttocks, limbs, feet and hands appeared to be more commonly affected in children with bleeding disorders than without. It is possible that bruises to the arms may result from handling young children with bleeding disorders during everyday care.

Surprisingly, the number and size of bruises in walking children with severe bleeding disorders did not vary with prophylaxis. It is possible that children on prophylaxis were allowed to be more active. Alternatively, children started on prophylaxis for haemarthroses may have been more prone to bruising, younger subjects may not have built up to full dose prophylaxis or insufficient numbers were investigated as prophylactic regimens vary between centres.

Study limitations include combining children with mild and moderate bleeding disorders because there were insufficient subjects to assess separately. It is likely that the bruise size and number would decrease as factor levels increased between moderately and mildly affected children and also within the mild group. There were insufficient subjects to investigate whether this was the case. Similarly there may have been unrecognised differences between type 1 and type 2 VWD. Bruises were reported by carers and so accuracy cannot be known with certainty. There was complete concordance between carer and researcher for bruise number and location when 40 collections from non-bleeding disorder children were assessed. The differences between carers' and researcher's estimates of bruise size were small, and it is unlikely that the differences in size could be entirely attributed to measurement errors; it is not known if the same pattern holds true for children with bleeding disorder. It is possible that parents of children with a bleeding disorder were more protective. If this was the case it would have had the tendency to reduce bruising and so the results reported may be underestimates. In all groups many bruises were recorded as exactly $1 \mathrm{~cm}$. This is likely due to rounding and potentially introduces some inaccuracies when reporting bruises as $>1 \mathrm{~cm}$ or $<1 \mathrm{~cm}$; further investigation is needed. The possibility that abuse occurred cannot be excluded, although the informed consent stated that any concerns would prompt a referral to child protective services. Two children had more bruises than expected and were reviewed by independent members of the local child protection team, and concerns regarding abuse excluded.

In conclusion, we show that bruises in premobile children with severe (but not mild/moderate) bleeding disorders are more common than in non-bleeding disorder children. Bruises of $>1 \mathrm{~cm}$ are much more common in premobile children with severe bleeding disorders. Bruises on the ears, eyes, cheeks, neck and genitalia are rare, even among severe bleeding disorders. This is the first study to document bruise number, location and size in young children with bleeding disorders with a longitudinal design, and compare them with children without a bleeding disorder.

Acknowledgements The authors thank all the families who contributed data and Ana Guerrero, Amy Jungmann and Cindy Wakefield.

Contributors PWC: designed the study, collected and interpreted data and wrote the first draft of the manuscript. MH: designed the study, collected and interpreted data and revised the manuscript. FDD: designed the study, analysed and interpreted data and revised the manuscript, had full access to all of the data in the study and takes responsibility for the integrity of the data and the accuracy of the data analysis. SM: designed the study, collected and interpreted data and revised the manuscript. RL: collected and interpreted data and revised the manuscript. AET: collected and interpreted data and revised the manuscript. JH: collected and interpreted data and revised the manuscript. EC: collected and interpreted data and revised the manuscript. VB: collected and interpreted data and revised the manuscript. AMK: designed the study, collected and interpreted data and revised the manuscript.

Funding The study was funded by the Medical Research Council UK reference G0601638 and received support from the UK Clinical Research Network and National Institute for Social Care and Health Research Wales. MH was supported by a clinical training fellowship from Baxter Healthcare UK.

Competing interests None declared.

Ethics approval Southampton Ethics Committee (05/MRE11/8) and IRB of Hospital for Sick Children Toronto (1000013885).

Provenance and peer review Not commissioned; externally peer reviewed. Data sharing statement All study data have been included in the manuscript

Open Access This is an Open Access article distributed in accordance with the terms of the Creative Commons Attribution (CC BY 4.0) license, which permits others to distribute, remix, adapt and build upon this work, for commercial use, provided the original work is properly cited. See: http://creativecommons.org/licenses/ by/4.0/

\section{REFERENCES}

1 Anderson JA, Thomas AE. Investigating easy bruising in a child. BMJ 2010;341: C4565.

2 Khair K, Liesner R. Bruising and bleeding in infants and children - a practical approach. Brit J Haematol 2006;133:221-31.

3 Liesner R, Hann I, Khair K. Non-accidental injury and the haematologist: the causes and investigation of easy bruising. Blood Coagul Fibrinolysis 2004;15(Suppl 1): S41-9.

4 Thomas AE. The bleeding child; is it NAI? Arch Dis Child 2004;89:1163-7. 
5 Maguire S, Mann MK, Sibert J, et al. Are there patterns of bruising in childhood which are diagnostic or suggestive of abuse? A systematic review. Arch Dis Child 2005;90:182-6.

6 Maguire S, Mann M. Systematic reviews of bruising in relation to child abuse-what have we learnt: an overview of review updates. Evid Based Child Health 2013;8:255-63.

7 Kemp AM, Dunstan F, Nuttall D, et al. Patterns of bruising in pre-school childrena longitudinal study. Arch Dis Child 2015;100:426-31.

8 Carpenter RF. The prevalence and distribution of bruising in babies. Arch Dis Child 1999;80:363-6.

9 Kemp AM, Maguire SA, Nuttall D, et al. Bruising in children who are assessed for suspected physical abuse. Arch Dis Child 2014;99:108-13.

10 Sugar NF, Taylor JA, Feldman KW. Bruises in infants and toddlers: Those who Don't cruise rarely bruise. Arch Pediatr Adolesc Med 1999;153:399-403.

11 Biss TT, Blanchette VS, Clark DS, et al. Quantitation of bleeding symptoms in children with von Willebrand disease: Use of a standardized pediatric bleeding questionnaire. J Thromb Haemost 2010;8:950-6.

12 Biss TT, Blanchette VS, Clark DS, et al. Use of a quantitative pediatric bleeding questionnaire to assess mucocutaneous bleeding symptoms in children with a platelet function disorder. J Thromb Haemost 2010;8:1416-19.
13 Bowman M, Riddel J, Rand ML, et al. Evaluation of the diagnostic utility for von Willebrand disease of a pediatric bleeding questionnaire. J Thromb Haemost 2009;7:1418-21.

14 Sadler JE. Von Willebrand disease type 1: a diagnosis in search of a disease. Blood 2003;101:2089-93.

15 Jackson J, Miller M, Moffatt $M$, et al. Bruising in children: Practice patterns of pediatric hematologists and child abuse pediatricians. Clin Pediatr (Phila) 2015;54:563-9.

$16 \mathrm{O}^{\prime}$ Hare AE, Eden OB. Bleeding disorders and non-accidental injury. Arch Dis Child 1984;59:860-4

17 Chang L, Tsai M. Craniofacial injuries from slip, trip, and fall accidents of children J Trauma 2007:63:70-4.

18 Murty O, Ming C, Ezani M, et al. Physical injuries in fatal and non-fatal child abuse cases: a review of 16 years with hands on experience of 2 years in Malaysia. Int J Med Toxicol Leg Med 2006;9:43.

19 Naidoo S. A profile of the oro-facial injuries in child physical abuse at a children's hospital. Child Abuse Negl 2000;24:521-34.

20 Pierce MC, Kaczor K, Aldridge S, et al. Bruising characteristics discriminating physical child abuse from accidental trauma. Pediatrics 2010;125: $67-74$. 